\title{
Pericallosal Aneurysms: Effectiveness of Endovascular Management
}

\section{Aneurisma pericaloso: eficácia do manejo endovascular}

\author{
Lucas Eduardo Bonadio ${ }^{1}$ Luis Renato Garcez Mello ${ }^{1}$ Vitor Hugo Tamiosso Boer ${ }^{1}$ Leandro Jose Haas ${ }^{1}$ \\ Celso Itiberê Carvalho Bernardes ${ }^{1}$ Danielle De Lara ${ }^{1}$ Filipe Laurindo Cabral ${ }^{2}$ Gabriel Hoher Peres ${ }^{2}$ \\ Stephanie Lindner ${ }^{2}$

\footnotetext{
${ }^{1}$ Department of Neurosurgery, Instituto Catarinense de Neurologia e Neurocirurgia, Hospital Santa Isabel, Blumenau, SC, Brazil

2 Department of Neurosurgery, Hospital Santa Isabel, Blumenau, SC, Brazil
}

\begin{abstract}
Address for correspondence Lucas Eduardo Bonadio, MD, Instituto Catarinense de Neurologia e Neurocirurgia, Rua Mal. Floriano Peixoto, 300 - Centro, Blumenau, Santa Catarina, 89010-500, Brazil (e-mail: lucasbonadio@hotmail.com).
\end{abstract}

Arq Bras Neurocir 2017;36:7-13.

\begin{abstract}
Keywords

- pericallosal aneurysm

- endovascular management
\end{abstract}

\section{Resumo}

received

September 19, 2016

accepted

November 24, 2016

published online

February 1, 2017
Objective Clarify the safety and efficacy of the endovascular treatment of distal anterior cerebral artery (DACA) aneurysms, reporting outcomes of the aneurysms coiled in our service were compared with series of microsurgical treatment. The impact of embolization on ruptured or unruptured aneurysms remains controversial according to the current data, considering aneurysm from this topography should be aggressively treated due to their high incidence of rupture, currently there is a tend to prefer endovascular treatment.

Methods We conducted a retrospective cohort study with 1092 patients admitted with cerebral aneurysm from October 2005 to March 2015 in our service. There were 31 cases of DACA aneurysms treated with the endovascular technique. These were compared with same topography aneurysms underwent to clipping.

Results A total of 21 (67\%) of 31 cases presented with ruptured aneurysms, 13 (59\%) suffered clinical or radiological vasospasms, with modified Rankin Scale (mRS) scores of $3-5$ in 7 patients (31\%), and 4 deaths (mRS 6), reaching $92 \%$ of occlusion at one year. Conclusion Endovascular approach is associated with high angiographic occlusion rates and security.

Objetivo Para esclarecer a segurança e eficácia do tratamento endovascular dos aneurismas distais da artéria cerebral anterior distal (DACA), foram relatados os resultados de aneurismas embolizados em nosso serviço e comparados com séries de tratamento microcirúrgico. O impacto da embolização em aneurisma roto ou não roto permanece controverso com base nos dados atuais, considerando que o aneurisma dessa topografia deve ser tratado agressivamente devido à elevada incidência de ruptura, há uma tendência em preferir tratamento endovascular.

Métodos Realizamos um estudo retrospectivo de 1092 pacientes admitidos com aneurisma cerebral entre Outubro de 2005 a Março de 2015 em nosso serviço. Haviam 


\section{Palavras-chave}

- aneurisma pericaloso

- manejo endovascular
31 casos de aneurisma da DACA tratados com a técnica endovascular. Estes foram comparados com aneurismas da mesma topografia tratados através de microcirurgia. Resultados Um total de 21 (67\%) dos 31 pacientes apresentaram aneurisma roto, 13 (59\%) sofreram vasoespasmo clínico ou radiológico, desfecho Escala de Rankin modificada (ERm) 3-5 em 7 (31\%) pacientes e 4 mortes (ERm 6). A taxa de oclusão imediata foi de $96 \%$ e a taxa de oclusão em um ano de $92 \%$ com apenas uma recanalização.

Conclusão A abordagem endovascular está associada com altas taxas de oclusão angiográfica e segurança no procedimento.

\section{Introduction}

Distal anterior cerebral artery (DACA) aneurysms, also called pericallosal or A2 aneurysms, are rare and comprise $\sim 1.5$ to $9 \%$ of all intracranial aneurysms. The ideal treatment should be aggressive occlusion due to the high tendency of rupture $\left(-\right.$ Fig. 1). ${ }^{1-3}$

Despite the classical microsurgical approach to those lesions, recent improvement on radiological equipment and modern endovascular techniques provided new options for the treatment of wide neck aneurysms, overcoming the vulnerability to rupture during the operative exposure, and increasing the rate of success with this technique to $92.2-100 \%{ }^{3-7}$

Since 2005, at our institution, we have been choosing the endovascular coiling technique for the treatment of all pericallosal artery aneurysms, including those associated with intracerebral hemorrhage (ICH). In order to investigate the safety and efficacy of this method when treating DACA aneurysms, we report the outcomes of the aneurysms coiled at our service and compare them with series of microsurgical treatment.

\section{Material and Methods}

Our institution is a tertiary medical center serving an area of middle valley in the state of Santa Catarina, Southern Brazil, with a population of 750,000 people. We conducted a retrospective cohort study including patients admitted to the hospital from October 2005 to March 2015. During this period, 1,092 patients with ruptured or unruptured aneurysms underwent endovascular procedures. This material was organized as a historical cohort that was statistically analyzed and compared with some pericallosal aneurysms series extracted from the database.

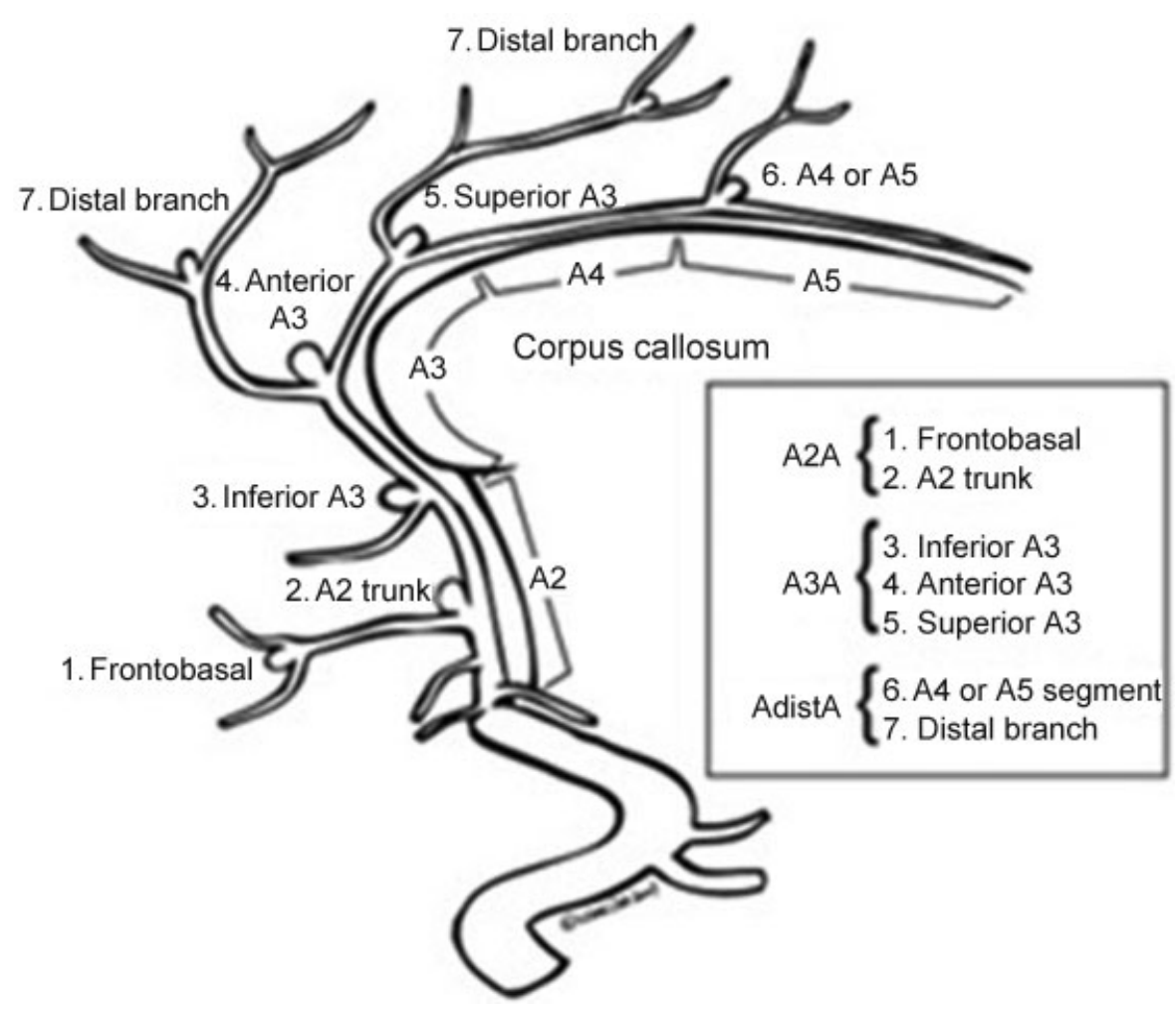

Fig. 1 Aneurysms of the pericallosal-callosomarginal junction. Source: Mann et al. ${ }^{2}$ (1984). 
Table 1 Modified Rankin Scale.

\begin{tabular}{|l|l|}
\hline & Modified Rankin Scale \\
\hline 0 & No symptoms \\
\hline 1 & $\begin{array}{l}\text { No significant disability, despite symptoms; able to } \\
\text { perform all usual duties and activities. }\end{array}$ \\
\hline 2 & $\begin{array}{l}\text { Slight disability; unable to perform all previous } \\
\text { activities but able to look after own affairs without } \\
\text { assistance. }\end{array}$ \\
\hline 3 & $\begin{array}{l}\text { Moderate disability; requires some help, but able } \\
\text { to walk without assistance. }\end{array}$ \\
\hline 4 & $\begin{array}{l}\text { Moderately severe disability; unable to walk with- } \\
\text { out assistance and unable to attend to own bodily } \\
\text { needs without assistance. }\end{array}$ \\
\hline 5 & $\begin{array}{l}\text { Severe disability; bedridden, incontinent, and re- } \\
\text { quires constant nursing care and attention. }\end{array}$ \\
\hline 6 & Death. \\
\hline
\end{tabular}

Source: van Swieten et al. ${ }^{27}$ (1988).

The post-procedural outcomes were measured using the modified Rankin scale (mRS, - Table 1) at discharge. An mRS score $\leq 2$ for ruptured aneurysms or no change from baseline for unruptured aneurysms was considered a good clinical outcome. $^{27}$

The angiographic demographic variables consisted on: ruptured/unruptured state; aneurysm size defined by longaxis measurement; and neck size and initial occlusion results. Every procedure was performed on a monoplane $\mathrm{C}$-arm angiographic system without 3D reconstruction. A procedure-related rupture was considered present if there was an extravasation of contrast during the coil embolization. A transcranial Doppler was performed for the diagnosis and outcome of the vasospasm. All aneurysms were treated using platinum coils or stent-assisted coiling. Only one neurosurgeon performed every procedures $(\mathrm{LJH})$.

The patients with ruptured aneurysms were evaluated by clinical grade Hunt-Hess (-Table 2) and Fischer scales for computed tomography (-Table 3 ). Furthermore, a neck size $\geq 4 \mathrm{~mm}$ indicates a wide-neck aneurysm, and the patients were divided into two groups: those with neck diameters $<3 \mathrm{~mm}$ and those with neck diameters $\geq 3 \mathrm{~mm}$. Re-rup-

Table 2 Hunt and Hess grading system for patients with subarachnoid hemorrhage

\begin{tabular}{|l|l|}
\hline Grade & Neurologic status \\
\hline 1 & $\begin{array}{l}\text { Asymptomatic or mild headache and slight nuchal } \\
\text { rigidity. }\end{array}$ \\
\hline 2 & $\begin{array}{l}\text { Severe headache, stiff neck, no neurologic deficit, } \\
\text { except cranial nerve palsy. }\end{array}$ \\
\hline 3 & Drowsy or confused, mild focal neurologic deficit. \\
\hline 4 & Stuporous, moderate or severe hemiparesis. \\
\hline 5 & Coma, decerebrate posturing. \\
\hline
\end{tabular}

Note: Based upon initial neurologic examination; adapted from Hunt, Hess $^{28}$ (1968).
Table 3 Fisher grade of cerebral vasospasm risk in subarachnoid hemorrhages

\begin{tabular}{|l|l|}
\hline Group & Appearance of blood on head CT scan \\
\hline 1 & No blood detected. \\
\hline 2 & $\begin{array}{l}\text { Diffuse deposition or thin layer with all vertical } \\
\text { layers (in the interhemispheric fissure, the insular } \\
\text { cistern, the ambient cistern) less than } 1 \mathrm{~mm} \text { thick. }\end{array}$ \\
\hline 3 & $\begin{array}{l}\text { Localized clot and/or vertical layers } 1 \mathrm{~mm} \text { or more } \\
\text { in thickness. }\end{array}$ \\
\hline 4 & $\begin{array}{l}\text { Intracerebral or intraventricular clot with diffuse or } \\
\text { no subarachnoid blood. }\end{array}$ \\
\hline
\end{tabular}

Abbreviation: $\mathrm{CT}$, computed tomography.

Source: Fisher et al. ${ }^{26}(1980)$.

tured aneurysms did not occur by this casuistic. The statistical analysis was performed with the chi-square test, considering as statistically significant values of $p<0.05$.

\section{Results}

Since 2005, our institution treated 1,092 patients with coiling aneurysms, with $2.74 \%(n=31)$ of them corresponding topography of DACA aneurysms, all confirmed on digital

Table 4 Ruptured versus unruptured, characteristics

\begin{tabular}{|l|l|l|}
\hline & Ruptured, $\boldsymbol{n}$ & Unruptured, $\boldsymbol{n}$ \\
\hline Totals & 21 & 10 \\
\hline Mean age & 53 & 57 \\
\hline & Sex & \\
\hline Male & 6 & 2 \\
\hline Female & 15 & 8 \\
\hline & Clinical presentation \\
\hline Hunt-Hess I-II & 15 & \\
\hline Hunt-Hess III & 4 & \\
\hline Hunt-Hess IV-V & 2 & \\
\hline & Aneurysm size \\
\hline$<10$ mm & 19 & 9 \\
\hline$\geq 10$ mm & 2 & 1 \\
\hline & Modified Fischer score \\
\hline $1-2$ & 9 & \\
\hline 3 & 6 & \\
\hline 4 & 6 & \\
\hline & Hospitalization (days) \\
\hline Average length & 6 & 2 \\
\hline & Rankin (mRs) \\
\hline $0-2$ & 10 & \\
\hline $3-5$ & 7 & 4 \\
\hline 6 & 4 & \\
\hline
\end{tabular}

Abbreviation: mRS, modified Rankin Scale. 
subtraction angiography (DSA). The demographic characteristics showed that the majority of patients were female $(n=23)$, and their average age was 54.6 years ( - Table 4 ). Twenty one $(67 \%)$ patients presented with ruptured aneurysms, and 13 (61\%) suffered clinical or radiological vasospasms. The analysis of the mRS scores at discharge of these ruptured aneurysms showed: 10 patients (47\%) with mRS scores $\leq 2$; mRS $3-5$ in 7 patients (33\%), and 4 deaths $(19 \%$, mRS 6) caused by severe vasospasm.

None of the ruptured aneurysms required emergency decompressive craniotomy or hematoma evacuation to avoid brain herniation, even though three patients presented hematoma.

Twenty eight patients had small aneurysms $(<10 \mathrm{~mm}$ in maximum diameter), and 6 of them were $<3 \mathrm{~mm}$. Another important variable to investigate is the size of the neck of aneurysm. In our study, all neck sizes were $\leq 4 \mathrm{~mm}$.

The patients were treated with coiling. Only one could not be treated (because of a proximal vasospasm), and this was considered a failure of treatment. No periprocedural symptomatic complications occurred. The immediate angiographic results showed complete aneurysm occlusion in all 30 cases of coil-treated aneurysms. There were thirteen controlled aneurysms, and angiographic obliteration was achieved in twelve of them with one year of follow-up. There was only one recanalization, which was recoiled immediately.

\section{Discussion}

The guidelines for the proper management of DACA aneurysms has changed over the past years, mainly due to improvements on the techniques, which were able to ensure security and minimal invasive procedures. In our institution, we have been performing endovascular coiling for unruptured and ruptured DACA aneurysms, including those associated with ICHs, as the first-line treatment. ${ }^{7-10}$

The most frequently reported site for aneurysms is the anterior communicating artery, which represents $36 \%$ of cases. Other locations include the middle cerebral artery
(26\%), the posterior communicating artery (18\%), and the internal carotid artery (10\%). Our database differs, with $20 \%$ of aneurysms of the posterior communicating artery, $18 \%$ of the anterior communicating artery, and $14 \%$ of the middle cerebral artery. Distal anterior cerebral artery aneurysms correspond to $2.74 \%$ of the total; it may not represent much, but the approach to them is changing, and we have been working to achieve security and efficacy with the endovascular treatment. ${ }^{11-13}$

Payner et al, in a cohort with 2,411 patients with aneurysms treated between 1998 to 2009, stated that the proportion of anterior communicating artery aneurysms managed with endovascular coiling increased from $6 \%$ to $38 \%$. Overall group comparisons showed no statistically significant difference between the average length of hospitalization for the patients who underwent endovascular coiling or clip ligation for their ruptured and unruptured aneurysms. In our institution, for the unruptured group, the average length of hospitalization is of two days for the coiling of aneurysms; in contrast, the unruptured group who underwent clipping had an average hospital stay of six days. ${ }^{13}$

The International Subarachnoid Aneurysm Trial (ISAT) demonstrated in 2002 that endovascular coiling for ruptured aneurysms with detachable coils was superior to surgical clipping by showing that a lower proportion of patients were dead or disabled after 1 year. We verified 4 (19\%) deaths (mRS 6 ) by vasospasm within 21 cases of subarachnoid hemorrhage (SAH), which is slightly larger than the percentage found in our database (13\%) for other aneurysm locations. Approximately $70 \%$ of the patients in this paper had $\mathrm{SAH}$, which probably contributes to the relatively high mortality rates (19\%) reported with the endovascular treatment of pericallosal aneurysms. $^{14-16}$

Based at our casuistic, when a comparison is made with the posterior communicating aneurysm, knowing it has an easy location for endovascular treatment, we testified similar rates of immediately occlusion. We found $96 \%$ immediate occlusion in 31 pericallosal aneurysms (-Figs. 2 and $\mathbf{3}$ ) excluding only due impossibility to access, this patient died due catastrophic vasospasm. This rate is superior to the one found by Keston (82\%)

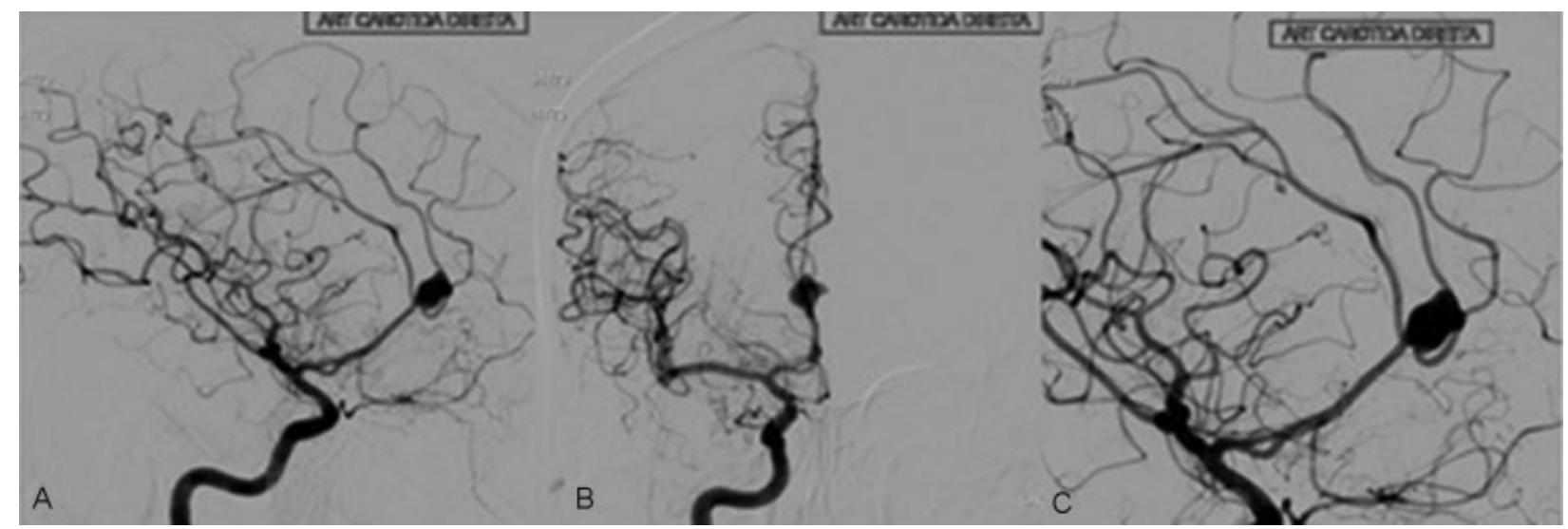

Fig. 2 Angiogram of a ruptured pericallosal aneurysm in a female patient, age 56. Lateral (A), anteroposterior (B) and lateral zoom (C) views of a selective injection of a right internal carotid artery. 


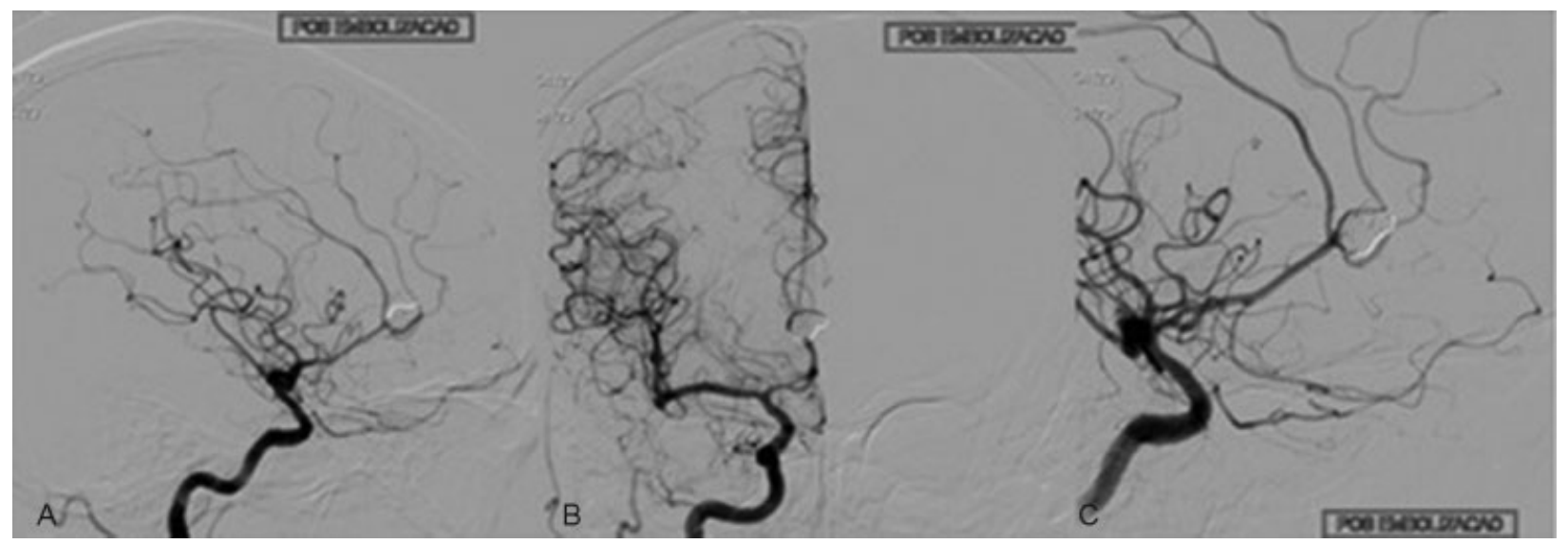

Fig. 3 Angiogram of a ruptured pericallosal aneurysm in a female patient, age 56, post embolization. Lateral (A), anteroposterior (B) and lateral zoom (C) views of a selective injection of the right internal carotid artery.

and Bilstra et al (89\%). In a surgical series, complete clipping of the aneurysmal neck was achieved in $90 \%$ of patients. ${ }^{11,17}$

In the study conducted by Hui et al, when outcomes were dichotomized to mRS 0-2 versus 3-6, there was a statistically significant difference, with coiling being more likely to produce a good outcome in patients with SAH. In the same study, all electively coiled pericallosal aneurysms (100\%) had an mRS score of 0 , and there was 1 patient (5\%) with an $\mathrm{mRS}$ score of 4 , and five patients (25\%) with mRS scores of $1-2$ in the clipped group. Regarding patients with SAH, 61\% (13/21) presented vasoespasms (-Fig. 4), and 47\% (10/21) presented a good recovery (mRS $0-2$ ), with moderate disability in $33 \%$ (7/21) (mRS 3-5) and a 19\% (4) mortality rate. In a surgical series, the author Orz described the outcome for 15 patients with ruptured aneurysms, he obtained Glasgow Outcome Scale between 1 and 4 (moderate disability and death) in $46 \%$, against $52 \%(11 / 21)$ reported in our series. ${ }^{3,8,9,18}$

Furthermore, in surgical groups, the aneurysmal neck was completely occluded without a residual neck in $90 \%$ of patients, while our series demonstrated $96 \%$ of complete occlusion. Small aneurysms corresponded to $90 \%$ of the cases ( $n=28)$ in our study. All DACA aneurysms, even if very small in size or discovered accidentally, should be aggressively treated because of their high tendency to rupture. To achieve security in surgery, Treynelis and Dunker proposed an interhemispheric approach with partial resection of the genu corpus callosum to achieve the proximal control, however this has made the approach aggressive. Several studies report that DACA aneurysms were considered a surgical challenge due to certain specific characteristics when compared with aneurysms located elsewhere. ${ }^{3,4,9,17,19}$

We treated ten unruptured aneurysms without periprocedural complications. Distal anterior cerebral artery aneurysms are usually small, and bleeding occurs irrespective of their size because of the lack of resistant arachnoid membranes at the level of the pericallosal cisterns. $3,9,17,19,20$ Therefore, we need to be aggressive, without complication, even Sturiale demonstrated in a systematic review a rate

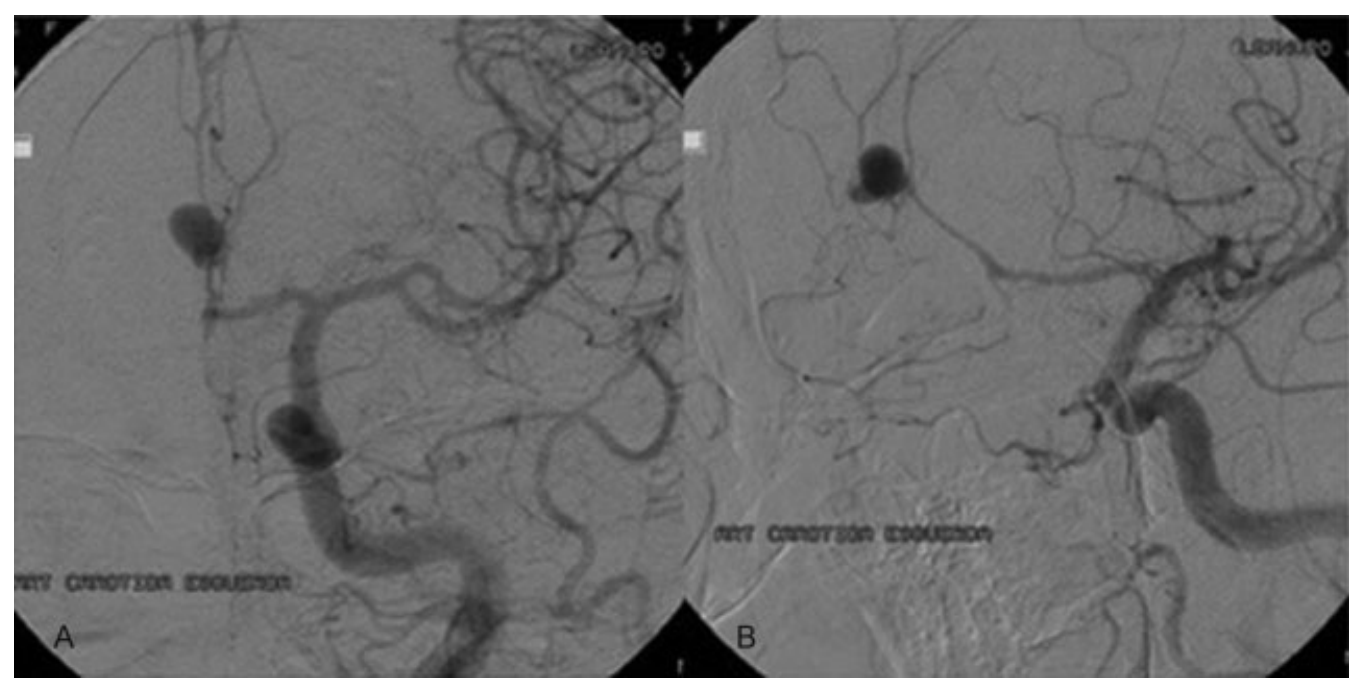

Fig. 4 Angiogram of a ruptured pericallosal aneurysm in a female patient, age 46, with an A1 vasospasm. Anteroposterior (A) and lateral (B) views of a selective injection of the left internal carotid artery. 


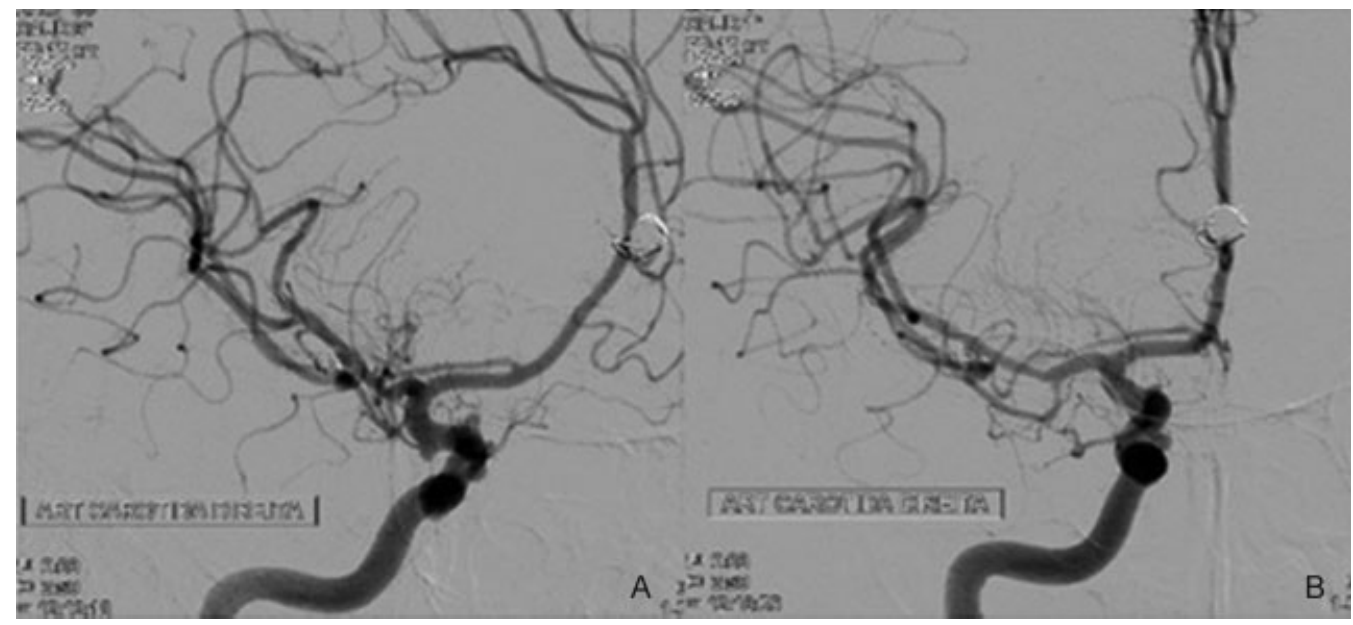

Fig. 5 Angiogram of an unruptured pericallosal aneurysm in a female patient, age 67, with multiple aneurysms. Lateral (A) and anteroposterior (B) views of a selective injection of the right internal carotid artery with a stent-assisted coiling technique.

nearly $7 \%$ of overall periprocedural rupture, with a procedure related morbidity rate of $8 \%$, higher than that of other circle of Willis aneurysms. ${ }^{7,21-23}$

Comparing the technical challenges posed by the endovascular management and clipping, both techniques present difficulties. Pericallosal artery aneurysms at the bifurcation represent a special endovascular technical challenge given their distal location, commonly wide-neck morphology, small parent vessel diameter and potentially high recurrence rate after coiling given the bifurcation location. But the microsurgical approach to peri + callosal aneurysms was considered difficult, because the proximal control is achieved relatively late in the dissection, and the dissection must take place throughout a very narrow and deep corridor. $3,9,17,19,24$

The introduction of new malleable microcatheters and microguidewires with improved trackability, pushability, and torque, together with the application of hydrophilic coating, has made the navigation into distant cerebral arteries easier. This possibility of associated techniques to occlude the aneurysm, such as, stent-assisted coiling ( - Fig. 5), in the study conducted by Darkhabani et al, could treat four patients with a Y-configuration stent-assisted coil embolization technique; all patients were successfully treated without significant technical difficulties. ${ }^{24,25}$

In our cases, no patients had large hematomas requiring emergency decompressive craniotomy or hematoma evacuation. Follow-up after one year was conducted in thirteen cases (-Fig. 6), with only one recanalization, which was immediately recoiled. Nguyen et al emphasized the recurrence rate of coiled DACA aneurysms, even though the rate was not significantly higher than the one for intracranial aneurysms coiled elsewhere. In a review of an ISAT cohort with 18 years of follow-up, Molyneux et al reported a small

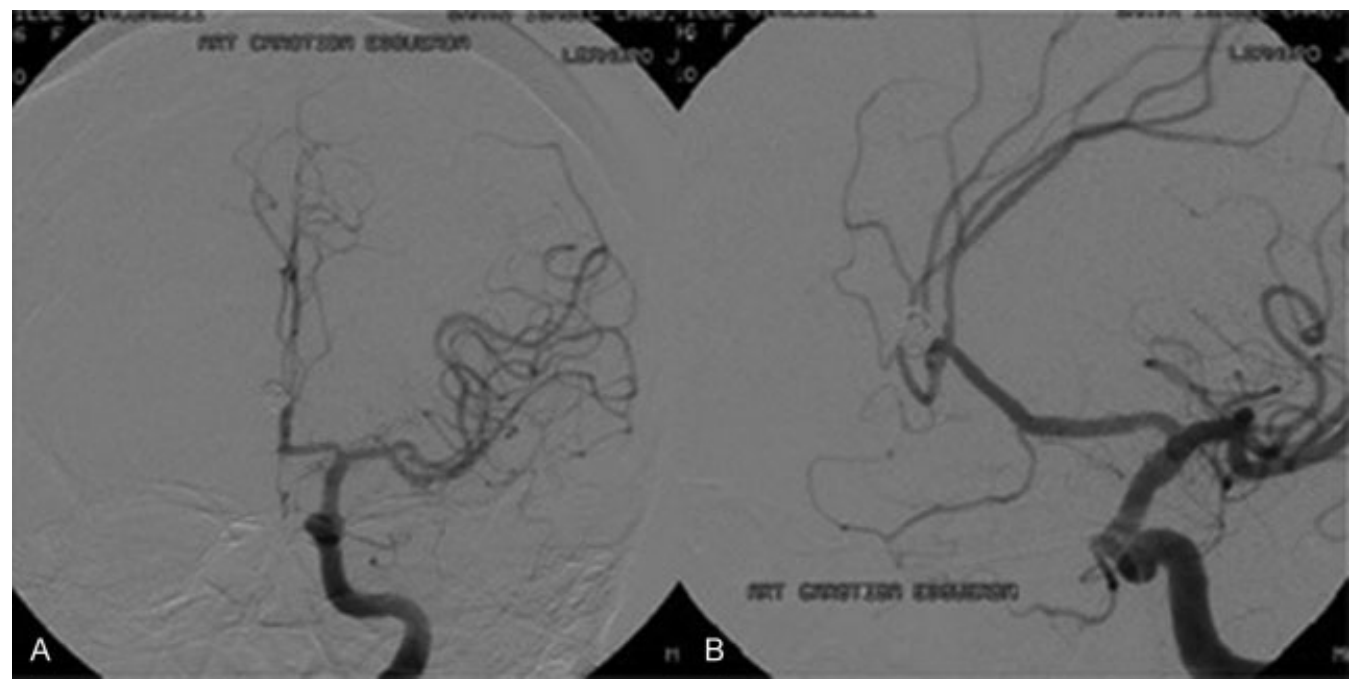

Fig. 6 Angiogram of a ruptured pericallosal aneurysm in a female patient, age 46, after 1 year of follow-up. Anteroposterior (A) and lateral (B) views of a selective injection of the left internal carotid artery. 
excess risk of subarachnoid hemorrhage recurrence from the target aneurysm in the endovascular group up to 17 years after the initial hemorrhage. However, this excess did not translate to a significantly worse clinical outcome when compared with the surgically treated group. The overall risk of death or dependency from a new bleeding did not differ between the groups. ${ }^{14,16,23}$

\section{Conclusion}

The endovascular management of DACA aneurysms has shown to be a safe technique, with good results, and it is performed in several centers worldwide. The same approach is followed for the presence of ICHs. The initial results of ISAT 2002 for the endovascular coiling in pericallosal artery aneurysms were not satisfactory, but we actually saw encouraging results regarding distal aneurysms. Microsurgical clipping is still the primary treatment modality for DACA aneurysms, however endovascular treatment shall be considered a good method.

\section{References}

1 Sekerci Z, Sanlı M, Ergün R, Oral N. Aneurysms of the distal anterior cerebral artery: a clinical series. Neurol Neurochir Pol 2011;45(2):115-120

2 Mann KS, Yue CP, Wong G. Aneurysms of the pericallosal-callosomarginal junction. Surg Neurol 1984;21(3):261-266

3 Orz Y. Surgical Strategies and outcomes for distal anterior cerebral arteries aneurysms. Asian J Neurosurg 2011;6(1):13-17

4 Nguyen TN, Raymond J, Roy D, et al. Endovascular treatment of pericallosal aneurysms. J Neurosurg 2007;107(5):973-976

5 Rodríguez-Hernández A, Zador Z, Rodríguez-Mena R, Lawton MT. Distal aneurysms of intracranial arteries: application of numerical nomenclature, predilection for cerebellar arteries, and results of surgical management. World Neurosurg 2013;80(01/02): 103-112

6 Pierot L, Boulin A, Castaings L, Rey A, Moret J. Endovascular treatment of pericallosal artery aneurysms. Neurol Res 1996;18(1):49-53

7 Sturiale CL, Brinjikji W, Murad MH, Cloft HJ, Kallmes DF, Lanzino G. Endovascular treatment of distal anterior cerebral artery aneurysms: single-center experience and a systematic review. AJNR Am J Neuroradiol 2013;34(12):2317-2320

8 Waldenberger P, Petersen J, Chemelli A, et al. Endovascular therapy of distal anterior cerebral artery aneurysms-an effective treatment option. Surg Neurol 2008;70(4):368-377

9 Hui FK, Schuette AJ, Moskowitz SI, et al. Microsurgical and endovascular management of pericallosal aneurysms. J Neurointerv Surg 2011;3(4):319-323

10 Vora N, Thomas AJ, Gupta R, et al. Endovascular treatment of distal anterior cerebral artery aneurysms: technical results and review of the literature. J Neuroimaging 2010;20(1):70-73

11 Keston P, White PM, Horribine L, Sellar R. The endovascular management of pericallosal artery aneurysms. J Neuroradiol 2004;31(5):384-390
12 Vivancos J, Gilo F, Frutos R, et al. Guía de actuación clínica en la hemorragia subaracnoidea. Sistemática diagnóstica y tratamiento. Neurologia 2012; doi: D10.1016/j.nrl.2012.07.009

13 Payner TD, Melamed I, Ansari S, et al. Trends over time in the management of 2253 patients with cerebral aneurysms: A single practice experience. Surg Neurol Int 2011;2:110

14 Molyneux A, Kerr R, Stratton I, et al; International Subarachnoid Aneurysm Trial (ISAT) Collaborative Group. International Subarachnoid Aneurysm Trial (ISAT) of neurosurgical clipping versus endovascular coiling in 2143 patients with ruptured intracranial aneurysms: a randomised trial. Lancet 2002;360(9342): $1267-1274$

15 Cavalcanti DD, Abla AA, Martirosyan NL, McDougall CG, Spetzler RF, Albuquerque FC. Endovascular management of distal ACA aneurysms: single-institution clinical experience in 22 consecutive patients and literature review. AJNR Am J Neuroradiol 2013; 34(8):1593-1599

16 Molyneux AJ, Birks J, Clarke A, Sneade M, Kerr RS. The durability of endovascular coiling versus neurosurgical clipping of ruptured cerebral aneurysms: 18 year follow-up of the UK cohort of the International Subarachnoid Aneurysm Trial (ISAT). Lancet 2015; 385(9969):691-697

17 Lee JY, Kim MK, Cho BM, Park SH, Oh SM. Surgical experience of the ruptured distal anterior cerebral artery aneurysms. J Korean Neurosurg Soc 2007;42(4):281-285

18 Proust F, Toussaint P, Hannequin D, Rabenenoïna C, Le Gars D, Fréger P. Outcome in 43 patients with distal anterior cerebral artery aneurysms. Stroke 1997;28(12):2405-2409

19 Kawashima M, Matsushima T, Sasaki T. Surgical strategy for distal anterior cerebral artery aneurysms: microsurgical anatomy. J Neurosurg 2003;99(3):517-525

20 Park KY, Kim BM, Lim YC, et al. The role of endovascular treatment for ruptured distal anterior cerebral artery aneurysms: comparison with microsurgical clipping. J Neuroimaging 2015;25(1): 81-86

21 Park HS, Kwon SC, Kim MH, Park ES, Sim HB, Lyo IU. Endovascular coil embolization of distal anterior cerebral artery aneurysms: angiographic and clinical follow-up results. Neurointervention 2013;8(2):87-91

22 Brilstra EH, Rinkel GJ, van der Graaf Y, van Rooij WJ, Algra A. Treatment of intracranial aneurysms by embolization with coils: a systematic review. Stroke 1999;30(2):470-476

23 Seibert B, Tummala RP, Chow R, Faridar A, Mousavi SA, Divani AA. Intracranial aneurysms: review of current treatment options and outcomes. Front Neurol 2011;2:45

24 Darkhabani ZM, Lazzaro MA, Zaidat OO. Pericallosal artery aneurysm treatment using Y-configuration stent-assisted coil embolization: a report of four cases. J Neurointerv Surg 2012;4(6):459-462

25 Menovsky T, van Rooij WJ, Sluzewski M, Wijnalda D. Coiling of ruptured pericallosal artery aneurysms. Neurosurgery 2002; 50(1):11-14

26 Fisher CM, Kistler JP, Davis JM. Relation of cerebral vasospasm to subarachnoid hemorrhage visualized by CT scanning. Neurosurg 1980;6:1-9

27 van Swieten JC, Koudstaal PJ, Visser MV, Schouten HJ, van Gijn J. Interobserver agreement for the assessment of handicap in stroke patients. Stroke 1988;19:604-607

28 Hunt WE, Hess RM. Surgical Risk as Related to Time of Intervention in the Repair of Intracranial Aneurysms. J Neurosurg 1988; 28(1):14-20 